\title{
Constructing physician-assisted dying: the politics of evidence from permissive jurisdictions in Carter v. Canada
}

\author{
Hadi Karsoho, David Kenneth Wright, Mary Ellen Macdonald \& Jennifer R. \\ Fishman
}

To cite this article: Hadi Karsoho, David Kenneth Wright, Mary Ellen Macdonald \& Jennifer R. Fishman (2017) Constructing physician-assisted dying: the politics of evidence from permissive jurisdictions in Carter v. Canada, Mortality, 22:1, 45-59, DOI: 10.1080/13576275.2016.1157061

To link to this article: http://dx.doi.org/10.1080/13576275.2016.1157061

\section{曲 Published online: 17 Mar 2016.}

\section{ש \\ Submit your article to this journal $\pi$}

Џ Article views: 535

Q View related articles

View Crossmark data $\rtimes$ 


\title{
Constructing physician-assisted dying: the politics of evidence from permissive jurisdictions in Carter v. Canada
}

\author{
Hadi Karsoho a , David Kenneth Wright ${ }^{\mathrm{b}}$, Mary Ellen Macdonald ${ }^{\mathrm{c}}$ and Jennifer R. \\ Fishman ${ }^{d}$
}

\begin{abstract}
a'Department of Sociology, Department of Social Studies of Medicine, McGill University, Montreal, Canada; ${ }^{b}$ Faculty of Health Sciences, School of Nursing, University of Ottawa, Ottawa, Canada; 'Faculty of Dentistry, Oral Health and Society Research Unit, McGill University, Montreal, Canada; ${ }^{\mathrm{d} D e p a r t m e n t ~ o f ~ S o c i a l ~ S t u d i e s ~ o f ~}$ Medicine, Biomedical Ethics Unit, Montreal, Canada
\end{abstract}

\begin{abstract}
Since the 1990s, there has been a growing global movement to legalise the controversial practice of physician-assisted dying (PAD). In the last twenty years, 13 jurisdictions have decriminalised or legalised PAD which, in turn, have produced new knowledge on the practice. The recent case of Carter v. Canada, which decriminalised PAD in Canada in 2015 , provides us with an empirical opportunity to investigate how actors deployed and interpreted this new knowledge. We found that actors used expert evidence from permissive jurisdictions to construct different meanings of PAD as a legalised medical practice. The opponents constructed PAD as a practice accessed by patients who were suicidal, performed by uncaring physicians unskilled in end-of-life care, and loosely regulated through a fallible regime. The proponents used the evidence to construct PAD as a practice borne out of a patient's rational choice, performed by caring physicians within an environment where end-of-life care had improved since legalisation, and tightly regulated through a regime where participants function as sentries overseeing each other's actions. In the final analysis, we argue that the proponents' success in this case contributed to the production and reproduction of a specific cultural script that renders PAD culturally appropriate.
\end{abstract}

\section{KEYWORDS}

Physician-assisted dying; euthanasia; assisted suicide; Carter v. Canada; culturally appropriate death; Canada

\section{Introduction}

Since the 1990s, there has been a growing global movement to legalise the controversial practice of physician-assisted dying (PAD), either in the form of euthanasia or physician-assisted suicide (PAS) (Flemming, 2005; Tierney, 2010). In the last twenty years, 13 jurisdictions have decriminalised or legalised PAD, most recently Canada in February 2015 and California in October 2015. Thus, while PAD is an ancient topic (Emanuel, 1994), the legal regimes of the practice are a relatively recent phenomenon. In the light of the newly'permissive jurisdictions', a sociological approach can bring a unique perspective to the study of PAD, one 
that does not aim to settle the normative questions on the practice but analyse instead the ways in which knowledge that emerged from those jurisdictions has been taken up by stakeholders in the debate over legalisation elsewhere.

The recent case of Carter v. Canada [Carter V. Canada (Attorney General) 2015 Scc 5, 468 N.R. 2015 SCC 5 1, 2015)] provides us with an empirical opportunity to investigate how actors in one case deployed and interpreted knowledge on legalised PAD from the permissive jurisdictions. Carter was a recent landmark litigation that found Canada's criminalisation of PAD to be unconstitutional, paving the way for a potential nationwide legalisation of the practice. On 6 February 2015, the Supreme Court of Canada (SCC) ruled unanimously that the Criminal Code prohibitions on PAD infringed on Canadians' constitutional rights to life, liberty and security. PAD, as defined in the case, constitutes both euthanasia, 'the intentional termination of life of a person, by another person, in order to relieve the first person's suffering' [Carter v. Canada (Attorney General), 2012 BCSC 886, 287 C.C.C. (3d) 1, (BCSC), p. 16] and PAS, 'the act of intentionally killing oneself with the assistance of a medical practitioner or a person acting under the direction of a medical practitioner, who provides the knowledge, means or both' (ibid., p. 16). ${ }^{1}$

In this article, we show how actors in the case used expert evidence from permissive jurisdictions to construct different meanings of PAD as a legalised medical practice. We begin by describing how the proponents used the evidence to reopen the legal debate on PAD in Canada, after which we describe the types of evidence used in the case as well as the nature of its production from different permissive jurisdictions. We then show how the opponents constructed PAD as a practice accessed by patients who were suicidal, performed by uncaring physicians unskilled in end-of-life care, and loosely regulated through a fallible regime where abuse could be concealed with the complicity of state authorities. The proponents, on the other hand, used the evidence to construct PAD as a practice borne out of a patient's rational choice, performed by caring physicians within an environment where end-of-life care had improved since legalisation, and tightly regulated through a regime where participants function as sentries overseeing each other's actions. In the last section, we argue that the proponents' success in this case contributes to the production and reproduction of a specific cultural script that renders PAD culturally appropriate in Canada.

\section{Reopening a closed debate and constructing new meanings of PAD}

Prior to Carter, Canada's medico-legal landscape on PAD had been shaped by the SCC's prior ruling on the issue in Rodriguez v. British Columbia [Rodriguez v. British Columbia (Attorney General), 3 S.C.R. 519, (Can.)] in 1993. Sue Rodriguez, diagnosed with Amyotrophic Lateral Sclerosis, had filed a constitutional challenge against the Criminal Code prohibitions on assisted suicide. Rodriguez was decided by a 5-4 vote in which the majority of the Justices found that the impugned prohibitions did indeed violate Sue Rodriguez's Charter rights to life, liberty and security of the person. However, the majority also found that the prohibitions were justified because the government had successfully demonstrated that nothing short of a blanket prohibition would protect the vulnerable from being induced to commit suicide in times of weakness. Rodriguez had thus closed the legal debate on PAD in Canada, at a time when a permissive regime did not yet exist anywhere in the world. ${ }^{2}$

The subsequent emergence of permissive jurisdictions in other countries was crucial to reopening the debate. ${ }^{3}$ In order for the courts to take up the issue of PAD anew, the 
proponents of legalisation had to show that there had been new 'facts' on the matter that did not exist when Rodriguez was decided twenty years ago. The legalisation of PAD in other jurisdictions had made possible the production of new data on the practice. Legalisation simultaneously creates the regulated practice, and by extension, new regulated subjects, and opens them up to social scientific inquiry. The proponents of legalisation in Canada were able to frame the new empirical data resulting from legalisation elsewhere as new expert evidence that they successfully used to reopen the debate.

In any litigation, expert evidence does not speak for itself. Instead, it must be communicated to the courts through witnesses. Cole (2007) has argued that the 'problem with experts for law is not so much what the evidence says, but what the expert says to the fact finder...I suggest that courts and scholars need to spend a little more time thinking about expert testimony and perhaps a little less time thinking about scientific evidence' (p. 818-19). Expert witnesses perform the crucial function of disciplining others into seeing reality in particular ways by establishing the particular'facts of the matter' that constitute that reality (Cole, 1998). A successful litigation such as Carter, therefore, has the potential to reshape our collective understanding of PAD. Such 'constitutive' effects of a legal action have long been recognised by sociolegal scholars (e.g. Mather, 1998). A legal action can change the social order of a phenomenon while simultaneously changing the meaning of that phenomenon. In other words, a legal action can produce a new cultural script through which we can come to understand a phenomenon differently. We therefore take up the question of how actors in one PAD litigation used the new knowledge arising from permissive jurisdictions to construct various contemporary meanings of PAD.

\section{Analytical approach}

Our analytical approach lies at the intersection of the sociology of scientific knowledge and 'configurational analysis of social action' (Jackson, 2014). In analysing the various claims produced by the actors in the case, we first adopt the methodological principle of symmetry first articulated by sociologists of scientific knowledge (Collins, 1983). This epistemological orientation to data analysis asks sociologists to be indifferent with respect to truth and falsity, rationality and irrationality, or success or failure (Potter, 1996). Consequently, we do not see our task in this study as adjudicating which actors or claims in the case were right or wrong. Rather, we attend closely to ways in which the 'truth' of PAD was discursively produced by the various actors.

In this study, we ran up against what Giddens has called the problem of the 'double hermeneutics' in social research: '[Analysts] have to interpret what is said by historical actors while keeping firmly in mind the fact that what they are interpreting are interpretations of the situations that those actors themselves have made' (1984 as cited in Jackson, 2014, p. 269). In other words, how does one produce a meaningful interpretation of actors' talk in which the substance of that talk is itself an interpretation of a specific reality? One way would be to conduct a 'configurational analysis of social action' where actors are understood to be 'cognitive bricoleur', building reality with the tools available to them (Jackson, 2014). According to this analytical approach, the work of empirical analysis 'should involve delineating the resources available [to actors] and tracing the ways that they are deployed in practice' (Jackson, 2014, p. 269). Specifically, Jackson (2014) calls for three analytical tasks: first, the cultural resources on which actors draw must be delineated; second, the history 
of those resources must be disclosed; and third, the specific ways in which those resources are deployed in a concrete episode must be traced.

\section{Data and methods}

This study is part of a larger research project of public controversies on medicalised dying in Canada. Data used for this article consist of the legal artefacts generated by the litigation and in-depth semi-structured interviews with key participants. The first and second authors Karsoho and Wright also attended and took observation notes at the SCC hearing on 15 October 2014. Data collection process spanned 21 months from July 2013 to March 2015. Prior to beginning data collection, this study received Institutional Review Board approval from McGill University.

The legal artefacts include trial transcripts, affidavits, factums and official judgments, amounting to over 4000 pages of text. We employed a purposive sampling strategy (Marvasti, 2004) to recruit participants for interviews. Our sampling strategy acknowledged that'actors are not born equal in controversies'(Venturini, 2010, p. 262), and our initial approach targeted only those participants who had the most impact in the case. We operationalised impact according to two criteria: those whose opinions were eventually cited by the Justices and those who were cross-examined. Our recruitment process resulted in 42 interviews with select plaintiffs, interveners, and witnesses. Informed consent, either written or verbal, was obtained from every participant.

Some participants declined to be identified by name, which presented us with a conundrum: on the one hand, all of the legal data are publicly accessible and yet some of the authors of this data whom we interviewed did not want to be publicly identified in our reports. In order to preserve their anonymity, we have decided to anonymise all data attributions, including the legal data. For each quotation presented in this article, we identify only the source of data (e.g. trial transcript, interview) and, where necessary for contextualisation, their professional role (e.g. bioethicist, palliative care physician) and/or geographic location. The only exception that we make concerns institutional actors (e.g. a representative of a right-to-die organisation). We feel that the identification of these organisations (not the personal identity of the representative) is important to the understanding of our analysis. All of the institutional actors we interviewed had given us permission to identify them and their organisations by name. It is worth noting that for the purpose of our analysis, our interest lies primarily not in the identity of each individual actor but rather the substantive contents of the discourses across various positions and professions.

For this article, we culled all data where discussions on expert evidence from permissive jurisdictions took place. These data were analysed, coded and re-coded inductively to a higher order 'interpretive codes' (Miles \& Huberman, 1994) by the first author using Atlas. $\mathrm{ti}^{\mathrm{TM}}$ and then presented to all of the authors for multiple rounds of further analysis. Our analysis for this article ultimately focused on what we term 'sustained moments of tension' between study participants on the issue of what PAD as a legal medical practice actually entailed. These were extended periods that occurred during the case (e.g. a cross-examination) and in our interviews where participants discursively challenged, deconstructed and reconstructed other actors' understandings of legalised PAD. ${ }^{4}$ The quotations that we have selected are representative of the most salient themes present in participants' sustained moments of tension. 


\section{Results}

We first delineate the evidence used by actors in the case and describe its historical production in the section below. In the following three sections, we discuss how our study participants engaged with the evidence to construct the meanings of PAD as a legalised medical practice that lay at three different analytical registers: at the levels of the patient, the physician and the regime itself.

\section{Expert evidence from permissive jurisdictions in Carter v. Canada}

In Carter, much of the expert evidence came from the first three jurisdictions to have already legalised a form of PAD: Oregon, the Netherlands and Belgium. Less evidence came from Washington State and from Switzerland. Expert evidence on Luxembourg and Colombia was not subject to extended discussion during the case. ${ }^{5}$ By the time Carter reached the SCC, the case had seen the participation of 97 witnesses and 26 interveners. One hundred eighteen affidavits were filed by the witnesses. Seventy-six were expert witnesses: 42 from Canada, 18 from the United States, 5 from the United Kingdom, 4 from Belgium, 3 from the Netherlands and 2 each from Switzerland and Australia. Eighteen expert witnesses were cross-examined on their affidavits, including 11 who were cross-examined before the trial judge.

In the rest of this section, we describe the variety of the content of the expert evidence in Carter, limiting our discussion to the evidence from Oregon, the Netherlands and Belgium on which most the discussions about PAD in permissive jurisdictions were based.

Legalisation opens up a newly regulated practice and subjects it to scientific inquiry and surveillance. In the context of PAD, legalisation does this in a number of ways. First, legalisation vests a governmental body with the authority to oversee the practice. In all permissive regimes, physicians are required to report all cases of PAD that they carry out. In the Netherlands, physicians report to one of the five Regional Review Committees (RCCs) which evaluates all reported cases to ascertain whether or not they fall within the boundaries of the Dutch law (Griffiths, Weyers, \& Adams, 2008). The RCCs are mandated to publish an annual joint report on all cases reviewed. In Belgium, the Law on Euthanasia created the Federal Control and Evaluation Commission that functions much like the RCCs in the Netherlands. In Oregon, physicians are to report to the Oregon Health Authority (OHA) all prescriptions for lethal medication (OHA, 2006). Reports of all PAS cases are published annually by the Authority. A new type of evidence - official government data - has, therefore, been made possible through legalisation.

Legalisation also allows for arenas of research by independent or arm's length academics regarding the practice of PAD. One of the most important studies of this type is the nationwide Dutch research on the prevalence of medical end-of-life decisions. An aim of this investigation was to arrive at a reliable estimate of the incidence of PAD. How these studies estimate the rate of euthanasia and other medical end-of-life decisions is beyond the scope of this article. Suffice it to say that these studies make it possible to calculate the reporting rate of PAD cases by comparing the number of cases self-reported by physicians to the oversight bodies and the number of cases estimated in the national studies. These studies have also 'uncovered' what the researchers called 'Life-ending Acts Without Explicit Request' of patients (LAWER). LAWER refers to a situation whereby the patient's death is the result of administration of drugs with the explicit intention on the part of the physician to 
hasten death but without the explicit legal request of a patient. Surveys that employ similar methodologies have also been conducted in Belgium (Griffiths, Weyers, \& Adams, 2008). Together with the official government data on PAD, these data can be considered the'primary data' upon which much of the expert evidence in Carter was based.

We further note that legalisation not only makes a practice visible but also visible to more actors. The primary data on PAD just described were then subject to secondary analysis and critiques by other stakeholders. Expert evidence based on these secondary analyses was less present but no less contested in Carter. Legalisation also enabled the descriptions of experts' professional experience working in permissive jurisdictions, which rounded out the body of expert evidence submitted in Carter. Collectively, the evidence provided actors with resources to mobilise claims about the relative incidence and safety of PAD, as well as professionals' experience with its associated practices, in permissive jurisdictions.

\section{Suicide or rational choice?}

Our analysis shows that the actors in the case engaged the evidence to construct competing understandings of the typical patient who would access PAD (the 'PAD patient'). Canada ${ }^{6}$ argued the PAD patient was likely to be motivated by depression or other psychiatric conditions, thereby seeing the request for PAD as suicidal ideation, deserving of mental health intervention rather than hastened death. Canada also saw the 'ambivalence' of patients who requested PAD in permissive jurisdictions as further evidence that a PAD request was a suicidal ideation. In both Oregon and Washington State, the government reports showed that not all of the patients who received prescription of lethal medication ended up using it. For one suicidologist testifying for Canada, this was indication that '[a]lthough we would like to believe that the decision to hasten death by someone suffering from a terminal illness or degenerative disease is unambivalent rational decision, different from the often changing decisions to commit suicide by people in good health, there is no basis in fact to support this contention' (emphases added, affidavit). Thus, if a PAD request was suicidal ideation, it followed that the act of PAD itself must be an act of suicide.

The construction of PAD as suicide was expressly intended to pathologise the practice. Hacking (2008) has noted that our contemporary conceptualisation of suicide is characterised by three distinct ideas: (1) suicide is caused by depression; (2) suicide thrives in a culture of despair; (3) attempted suicide can be understood as a cry for help. If a PAD request could be seen as a 'cry for help', then the appropriate medical intervention would be psychiatric or psychological, rather than an 'early death' (affidavit). A clinical psychologist testifying for Canada stated under cross-examination: 'I think that anybody who would request PAD under any circumstances could be referred for a mental health assessment' (trial transcript).

In stark contrast to Canada's portrayal of PAD as a suicidal act, the claimants ${ }^{7}$ presented a view of PAD as a thoughtful and deliberate choice that reflected a set of life-long values emphasising autonomy and self-determination. On this view, patients seeking PAD have 'strong and vivid personalities characterised by determination and inflexibility. These individuals have an unusually fervent desire to control the timing and manner of death to avoid dependence on others. These preferences [reflect] pervasive and long-standing coping and personality traits' (affidavit). One retired Oregon physician also emphasised Oregon's exclusion of people with mental health issues from the PAD regime. 
The construction of the PAD patient as rational and not suffering from depression led many of the claimants' expert witnesses to insist that PAD was, in fact, not suicide. As one witness deposed: 'I submit that there is a difference between well-reasoned deliberation about controlling one's final days in the face of inevitable and imminent death (aid-in-dying) and suicides performed in the context of severe depression, despair and hopelessness and that evidence and argument submitted by [Canada's expert witnesses] conflate the two concepts' (affidavit). The claimants even questioned Canada's construction of the PAD patient as desiring death. Gloria Taylor was one of the plaintiffs; she had been diagnosed with ALS and stated, 'I am dying. I do not want to, but I am going to die; that is a fact' (emphases added, affidavit).

The debate over PAD as a suicide or rational act was reflected in the struggle among our study participants over the label 'PAS'. At the beginning of an interview with an Oregon physician who had testified for the claimants, the participant asked whether she could get us 'to use physician-assisted death or PAD' instead of PAS, explaining that she had found the term PAS to be'very offensive' (interviewee 28). The first annual report prepared by the OHA had used the term PAS. By 2007, however, the OHA began to use the term 'DWDA [Death with Dignity Act] death' instead to describe deaths under the Act. Compassion \& Choices Oregon , a right-to-die advocacy group, had acknowledged to us that they were responsible for asking the state to change the name (interviewee 8). For one of Canada's expert witnesses, Compassion and Choices' act and the official change in name amounted to'verbal engineering' designed to 'desensitise the public to what is actually going on, which is PAS. Because medical killing is always unpleasant, and suicide is always a tragedy' (interviewee 21). For Canada and its supporters, PAD was suicide, an act taken by a vulnerable patient; the use of terms other than PAS (e.g. PAD, death with dignity, aid in dying) could only be seen as an effort to mask what was 'actually going on (interviewee 21)'. For the claimants, however, PAD was a rational act, taken voluntarily by determined patients whose request fit with their larger life-long set of goals. ${ }^{8}$

\section{Professional (In)expertise in end-of-life care}

One fundamental disagreement between the claimants and Canada concerned what it meant for a physician to have moral and clinical expertise in end-of-life care. This disagreement played out most vividly in discussions on two subjects: first, patient's decision-making competency and second, palliative care.

There are multiple factors that could affect a patient's competency in decision-making. One that was raised frequently by Canada was the potential impact of depression and other psychiatric conditions on patient's competency. An Oregon physician who was an expert witness for Canada relayed the following story in his affidavit: a 76-year-old patient, for whom he was the family physician for over ten years, was diagnosed with malignant melanoma. He referred the patient to both radiation and medical oncology. After treating the patient, the radiation oncologist noted in her record that the patient was depressed. The patient subsequently asked his medical oncologist for lethal medication prescription under the law. The medical oncologist contacted the expert witness and asked him to be the consulting physician as required by ODDA. He refused. Nevertheless, according to the witness, a second opinion was sought and obtained elsewhere and the patient subsequently died from a'lethal 
overdose prescribed by the medical oncologist' (affidavit). This experience rent asunder the witness' relationship with the medical oncologist:

The medical oncologist who prescribed a lethal dose of medication for my patient had known and been treating him for only a few weeks. The professional relationship between the medical oncologist and myself was destroyed. I no longer trusted her and have never referred a patient to her again. Based on this experience, I believe that the tragedy of the system in Oregon is that instead of doing the right thing, which is to provide excellent care, patients'lives are being cut short by physicians who are not addressing the issues underlying patient suicidality at the end of life (affidavit).

Note how the witness pointedly referred to how medical oncologist had known his patient for only a few weeks, in contrast to the ten-year relationship he had cultivated. The witness' description was meant to convey not only that PAD was not the right intervention for the patient but also a sense of betrayal and disappointment rooted in the perceived inadequacy of care provided by the medical oncologist. This point was made all the more revealing when he added that in 'my experience, when I take the time and connect with my patient, I learn what is important to them, what makes their life have meaning, and what is underlying their request for suicide' (emphases added, affidavit).

Canada also characterised PAD as a medical practice borne out of professional inexpertise in palliative care. The fields of end-of-life care in the permissive jurisdictions were perceived by Canada to be a zero-sum game whereby the legal availability of PAD had caused a concomitant reduction in the quality of palliative care delivered there. This negative impact could be observed at both the individual (i.e. skills and knowledge) and systemic (i.e. support given to palliative care as a speciality) levels. A palliative care physician testifying for Canada took to the witness stand and recounted two incidents from his experience working and teaching at a Swiss university hospital. He had organised a palliative care workshop that was sparsely attended. He had also designed an optional palliative care course that received poor uptake by the physicians at the hospital. When he inquired into the reason for the poor reception of the workshop and the course, he was informed that 'there was someone who said, "well, I guess I don't have to do this if there is access to assisted suicide" (trial transcript). Canada further emphasised that what was needed in caring for patients at the end of life was not just any type of palliative care but 'specialist palliative care'. Canada relied heavily on many narratives of professionals' experience in permissive jurisdictions to construct PAD as a medical practice delivered by uncaring, unskilful physicians within a structural environment in which palliative care had been devalued because of the legal availability of PAD.

The claimants, on the other hand, constructed a picture of PAD as practiced not by incompetent physicians but by empathetic, compassionate professionals. During her cross-examination, a researcher from Oregon expounded on one study of Oregon psychiatrists' attitudes towards PAS. She explained that the study revealed that those psychiatrists supportive of the law 'actually wanted - potentially wanted assisted suicide for themselves' (trial transcript). Three-quarters of the psychiatrists sampled in the study stated that they would like the option of PAS for themselves; these were the psychiatrists who were more likely to support Oregon Death with Dignity Act and to feel that they could determine the patient's needs. 'So it may be that they were more empathetic to the patients that they could understand how it was possible to want assisted suicide', the witness concluded. In this way, PAD could be seen to be an expression of a professional ethics of care. 
With regard to palliative care in permissive jurisdictions, a palliative care physician described Belgium as having a different 'philosophy' in which there was a lower 'threshold of access to palliative care' for patients and in which palliative care competency was dispersed more widely throughout the health care system rather than concentrated within a select group of professionals (interviewee 11). So while'the professional technicality of that care is not the same as a very renowned and top palliative care services like at McGill, you know the tradition of Balfour Mount and all that', patients in permissive jurisdiction were still receiving good palliative care as'part of normal medical care.. ${ }^{9}$ As stated by a Dutch bioethicist, '[s]o we want a general physician to be able to perform palliative care; we want an oncologist to be able to perform palliative care; we want a nursing home physician to be able to give good palliative care' (interviewee 5). The claimants thus emphasised the importance of primary, rather than, specialist palliative care in end-of-life care.

Some witnesses for the claimants went so far as to argue that palliative care had improved in permissive jurisdictions because of legalisation. The improvement, they claimed, had come about paradoxically through the antagonistic stance taken by many of those in the palliative care community. Wright, Fishman, Karsoho, Sandham, and Macdonald (2015) have observed that many in the palliative care community are opposed to the ethics of PAD. As one witness from Washington state said, 'there is this philosophy that many of these [palliative care] providers have, whether right or wrong, that they believe that if they do a better job at managing their, palliating their patients' pain and symptoms, that patients won't choose the option of 'death with dignity" (interviewee 6). He believed that these palliative care providers had allowed their own moral-political opposition to'colour their professional judgment', but such opposition had actually resulted in 'more aggressive palliative care and better symptom management'. In other words, health care providers made conscious efforts to provide better palliative care with the hope that patients would not resort to PAD; such efforts were seen to have inadvertently resulted in the overall improvement of end-of-life care in permissive jurisdictions. The claimants thus constructed PAD as a practice that could exist alongside good palliative care.

\section{Regulating PAD}

In the preceding two sections, we have shown how participants' engagement with the evidence evinced competing understandings of the patients and the physicians implicated in PAD. In this section, we discuss divergent understandings of PAD as an institutional product. Participants used evidence from permissive jurisdictions to evaluate the overall functioning of the regimes and to scrutinise the relationship of different players within them. As mentioned previously, all of the PAD regimes' data rely on a posteriori reporting by physicians. This feature of the regimes, for Canada, constituted a systemic flaw through which problematic abuse could be made to disappear. An anti-PAD group, the Euthanasia Prevention Coalition (EPC), along with its provincial affiliate the EPC British Columbia, intervened in support of Canada's position. The executive director of EPC stated that while 'the official reports of euthanasia deaths for the most part appear to be reasonably safe' (interviewee 4), he would not adopt the conclusion that the regimes had not inflicted any harm. He asked rhetorically, 'where did the data come from? The data came from the reports from the doctors who did the euthanasia', implying that physicians might be reporting that they had followed the due care requirements when, in fact, they had not. 
Canada contended, as well, that the official data might not account for all cases of PAD. We had discussed earlier the nationwide studies on medical end-of-life decisions in Belgium and the Netherlands. Referencing this research, the EPC stated that the 'most staggering fact remains that after 9 years of legalised euthanasia in the Netherlands, $23 \%$ of deaths continue to go unreported and up to $47 \%$ go unreported in Belgium' (factum). The official data were, therefore, conceptualised as partial in both senses of the word: biased, because it may be masking abuse by physicians, and incomplete, because they represented only a sliver of the reality of PAD.

State authorities in particular were deemed by some of Canada's expert witnesses to be complicit in what they saw as physicians' abuse of the law. As previously discussed, the nationwide studies in medical end-of-life decisions in the Netherlands and Belgium enabled researchers to 'uncover' the practice of Life-Ending Act Without Explicit Request of Patient (LAWER). Canada interpreted LAWER to be non-voluntary euthanasia, and therefore, evidence of a slippery slope towards the countenance of a morally suspect practice that could put the vulnerable at risk. When asked by the trial judge why he thought LAWER could have taken place in the Netherlands, a psychiatrist testifying for Canada replied:

We have certain guidelines but they're not enforced so the net result is people get away with murder. It encourages them to do it. The guidelines don't help because they just see that nothing can happen. Nobody regulates it in a strong way (trial transcript).

For this participant, the regulation that resulted from legalisation actually provided a legal fig leaf to those physicians who 'get away with murder [i.e. LAWER]'. Moreover, he saw the state as failing to enforce the regulation, further encouraging physicians' abuse of the law. Here, Canada used one body of evidence to question the credibility and validity of the government data, thereby questioning the moral integrity of the regimes. In their final submission to the SCC, Canada stated that 'paper safeguards are only strong as the human hands that carry them out.' In arguing that the official data were partial and emphasising what they saw to be the failing of the state, Canada cast aspersions on the 'human hands' of the regimes, constructing PAD to be the sum of the regimes' fallible parts.

The claimants, on the other hand, emphasised PAD as the product of a regime in which in the participants were conceptualised as interlocking parts and in which individual actions must be seen as dependent on and consequential to the actions of other players within the regime. When discussing the criticism that the self-reporting feature of the Dutch regime could be masking evidence of abuse, a Dutch bioethicist pointed out that the regime did not rely exclusively on self-reporting by the attending physician:

[The Dutch regime] relies on self-reporting, but no, not only, and not exclusively because a second physician has to visit the patient and talk with the patient independently, has to write his or her own report, and it's not just the self-report. You also have to send in the complete medical file of your patient, and of course everything can be forged, but I don't believe that any physician would make such a "Truman Show," so the, if there are any inconsistencies, then the assessment committee will be able to find them (interviewee 5).

For this participant, then the regulation of PAD occurs at multiple locations involving multiple actors who function in essence as sentries overseeing the actions of other actors. One of the claimants' expert witnesses from Oregon expressed just this point when he said that: 'You would think, after more than a decade and a half, at least somebody would come forward and say that this was amiss, this was wrong, this was terrible (interviewee 8)'. 


\section{Discussion: making PAD culturally appropriate}

We have shown the roles that new knowledge from permissive jurisdictions played in the legalisation debate in Canada. Legalisation of PAD produces new subjects (PAD patients and other actors implicated in the regime) and, at the same time, produces a structure under which a practice is enacted. These subjects and the legalised medical practices become amenable to observation and inquiry by different actors (state officials, researchers, physicians) giving rise to new forms of knowledge about PAD. The new knowledge may then be taken up by the stakeholders as 'evidence' in the debate over legalisation in other empirical settings in multiple ways and for various purposes. The proponents in particular used these new data to reopen the legal debate on PAD that had previously been closed by Rodriguez. Their success has implications for other closed legal debates on PAD elsewhere.

Our analysis contributes to studies on how the meanings of PAD have been constructed over time. Research from this body of literature has shown that the meaning of PAD is historically contingent (Lavi, 2007; Van Hooff, 2004). In this article, we show how knowledge that has emerged only in the past twenty years can be deployed as new epistemic resources through which stakeholders construct competing contemporary understandings of the reality of PAD. Court proceedings are an excellent empirical site for observing such process of reality construction (Scheffer, 2007). The adversarial nature of the legal process lends itself to the construction and deconstruction of facts, turning court trials into what Lynch (1998, p. 830) has called 'a veritable sociology of knowledge machine'. We have observed just such a process in Carter; our analysis shows the actors in the case engaged with expert evidence from permissive jurisdictions around three central tensions: (1) whether patients who seek PAD are suicidal or rational; (2) whether physicians who enact PAD are competent in endof-life care; and (3) whether structures of oversight can safely regulate PAD.

The ostensible purpose of the proponents' use of expert evidence was to make the legal point that 'a permissive regime with properly designed and administered safeguards was capable of protecting vulnerable people from abuse and error' (Carter v. Canada (Attorney General), 2015 SCC 5, 468 N.R. 1, (Can.), 65). They succeeded to persuade the courts on this point. ${ }^{10} \mathrm{~A}$ full accounting of why the claimants succeeded would need to take into account their argument on the evolution of Canadian legal principles, which is beyond the scope of this article. Their success has important implications, however, for our collective understanding of PAD. The court is, after all, a regime of truth production, a foundational institution in society that is able to make publicly legitimised authoritative claims to the production of 'true' knowledge and facts on a phenomenon (Latour, 2010). We suggest that the courts' acceptance of the proponents' claims has contributed to the production and reproduction of a specific cultural script that renders deaths from PAD 'culturally appropriate'.

The notion of 'culturally appropriate death' was first elaborated by Timmermans (2005) in his study of medical death experts. Timmermans shows how in cases of 'apparently senseless deaths'(2005, p. 995) - such as those in sudden deaths - medical experts perform a variety of activities to render those deaths explainable and meaningful to relatives and other actors, activities that he terms 'death brokering'. In other words, death brokering renders the deaths of patients culturally appropriate. Pertinent to our analysis is Timmermans' insight that a culturally appropriate death relies on cultural scripts imbuing death with positive meanings that resonate with widely shared societal values and norms (see also Seale, 1998). Similarly, we argue that the ways in which the proponents of legalisation used the knowledge from 
permissive jurisdictions as new epistemic resources have contributed to the production and reproduction of a specific cultural script for what it means to be dying by way of PAD. In this script, deaths via PAD are made culturally appropriate because patients are rational and thus not suicidal; a patient's request is part and parcel of his/her personal values system; the practice is carried out by caring, empathic physicians within a structural context where palliative care can thrive alongside PAD; and the practice is produced through a reliable regime where the involvement of multiple actors is seen to constitute the safeguards.

Our methodologically symmetrical approach to the data has allowed us to see as well the opponents' constructions of PAD. We have deliberately included an analysis of the opponents' constructions because 'the believability of social constructions ... depends on what the [construction] expels to the outside. In this sense, social constructions are, at once, constituted and haunted by what they exclude' (Pfohl, 2008, p. 646). Prior to the emergence and wide circulation of the new knowledge from permissive jurisdictions, many commentators had constructed the narrative of PAD as one in which patients at the end of life would be driven to PAD because of untreated pain or depression (e.g. Cherny, 1996; Walker, 2003; Wolf, 1997). The history of Nazi physicians' abuse has also imbued euthanasia with a lasting eugenics connotation (Dowbiggin, 2003). Indeed, these meanings were reproduced in Canada's claims throughout Carter whereby patients were seen as suicidal; the practice was born of professional inexpertise in end-of-life care, and where abuse could be made to disappear with the complicit action of the state. Nonetheless, these constructions ultimately failed in achieving the hybrid legal-scientific status of 'facts' and were expelled 'to the outside' by the courts. Our analysis thus accords with the sociolegal literature that argues a change in the meaning of the contested phenomenon is a necessary precondition to social change (Beckett \& Hoffman, 2005). The success of the proponents in the court was a crucial step towards the larger social change of PAD.

The proponents' efforts at legalisation, however, did not unfold in a landscape of their own making. As Beckett and Hoffman (2005) have argued, cultural meanings are not infinitely plastic. Proponents had to learn to invoke existing dominant positive categories and symbols to persuade their audience. The proponents' script of PAD resonates morally and emotionally with the 'increasing individualism of modern values' (Deflem, 2008, p. 199). They also found resonance with the positive values of the postmodern good death that include, among others, privacy, dignity, independence, personal growth and informed choice (Walter, 1994). Medicine, too, has come to occupy a central place in the contemporary death and dying experience; as such, there is very little room to create narratives of death and dying outside of the biomedical context (Seymour, 2007). More specifically, the proponents could not dispense with the institution and ethos of palliative care that have come to dominate endof-life care (Livne, 2014). Thus, the proponents needed to enfold palliative care into their script of PAD in order to make it culturally appropriate.

Carter v. Canada is but one in a series of recent attempts to decriminalise and legalise PAD. In May 2015, the High Court of New Zealand heard a case brought by a woman against the country's legal prohibitions on PAD. Johnston (2015) observes that the New Zealand case has been buoyed by the success of the proponents of legalisation in Carter. In North America, the governor of California signed the End of Life Option Act on 5 October 2015 legalising PAS in that state. It seems to us that the legalisation effort will continue unabated in many different parts of the Western world in the foreseeable future. Of course, not all of these efforts have been or will be successful. The Irish Supreme Court, for example, recently 
upheld the Criminal Law prohibitions on assisted suicide [Fleming v. Ireland, 2013 IESC 19 (BAILII)]. Future observers would do well to look closely at the variations in the ways data and knowledge from permissive jurisdictions are used by stakeholders to construct various contemporary meanings in both successful and failed legalisation debates.

\section{Disclosure Statement}

No potential conflict of interest was reported by the authors.

\section{Notes}

1 Carter began in the British Columbia Supreme Court in 2011 where Smith J. found for the plaintiffs, a decision that was later overturned by the British Columbia Court of Appeal in 2013. The SCC granted claimants leave to appeal and heard the case on 15 October 2014. In the aftermath of the ruling, the federal government was given 16 months to amend the Criminal Code before the impugned prohibitions become null and void in the context of PAD.

2 This is not to say that the debate on PAD did not continue in other spheres of Canadian society. Since 1993, six private members' bills to legalise PAD had been introduced in Parliament.

3 These jurisdictions are as follows: The American states of Oregon, Washington, Montana, Vermont, New Mexico and California, the Northern Territory of Australia (later overturned by Canberra), Colombia, the Netherlands, Belgium, Luxembourg, and Switzerland.

4 We recognise differences in the processes that produced the legal, documentary data and the interview data as well as the different types of sociological claims that could be made with each type of data. In this study, however, the in-depth interviewing was designed from the outset to'speak' directly to the legal data. The interview guide for each participant was tailored according to that participant's legal data (i.e. the participant's factum, affidavit or examination transcript). The interviews thus provided not only depth and nuance to the legal data, but another discursive opportunity for the participants to construct the reality of PAD in particular ways.

5 Only PAS is legal in Oregon and Washington. Colombia has decriminalised euthanasia only. In Switzerland, assisting a person to commit suicide is not a crime so long as it is done for unselfish reasons. The Netherlands and Luxembourg have legalised both euthanasia and PAS. In Belgium, while the law explicitly mentions euthanasia only, the oversight body has allowed for PAS.

6 To stay close to the data, we use the term 'Canada' here to refer to the opponents (i.e. the Attorney General of Canada along with its witnesses and interveners supporting its position).

7 'Claimants' refer to the proponents (i.e. the plaintiffs along with their witnesses and interveners supporting their position).

8 This is not to imply that our study participants did not make distinctions between euthanasia and PAS. All of the actors involved in the case recognised the practical and policy distinctions between euthanasia and PAS.

9 Balfour Mount is widely acknowledged to be a palliative care pioneer in North America (Youk, 2004). In 1974, he established one of the first palliative care units in Canada at the Royal Victoria Hospital, part of McGill University Health Centre in Montreal. In Canada, palliative care exists as an official sub-specialty of medicine.

10 In their decision, the SCC Justices agreed with the findings of Smith J., the trial judge, stating that she 'made no palpable and overriding error in concluding, on the basis of evidence from scientists, medical practitioners and others who are familiar with end-of-life decision-making in Canada and abroad, that a permissive regime with properly designed and administered safeguards was capable of protecting vulnerable people from abuse and error' [Carter v. Canada (Attorney General), 2015 SCC 5, 468 N.R. 1, (Can.), 10]. 


\section{Acknowledgements}

We are grateful for the works of our two research assistants, Sarah Sandham and Kimberly Seida. We also thank Angela Campbell and the two anonymous reviewers for their helpful feedback. An earlier version of this paper was presented at the Canadian Sociological Association annual meeting in May 2015.

\section{Funding}

This work was supported by the Canadian Institutes of Health Research [grant number 114992].

\section{References}

Beckett, K., \& Hoffman, B. (2005). Challenging medicine: Law, resistance, and the cultural politics of childbirth. Law \& Society Review, 39, 125-169.

Carter v. Canada (Attorney General). (2012). BCSC 886, 287 C.C.C. (3d) 1, (BCSC).

Carter v. Canada (Attorney General). (2015). SCC 5, 468 N.R. 1, (Can.).

Cherny, N. I. (1996). The problem of inadequately relieved suffering. Journal of Social Issues, 52, 13-30.

Cole, S. A. (1998). Witnessing identification latent fingerprinting evidence and expert knowledge. Social Studies of Science, $28,687-712$.

Cole, S. A. (2007). Where the rubber meets the road: Thinking about expert evidence as expert testimony. Villanova Law Review, 52, 803-842.

Collins, H. M. (1983). An empirical relativist programme in the sociology of scientific knowledge. In K. Knorr-Cetina \& M. J. Mulkay (Eds.), Science observed : perspectives on the social study of science (pp. 85-114). London: Sage.

Deflem, M. (2008). Law and culture: The balance of values through norms Sociology of law: Visions of a scholarly tradition. Cambridge; New York, NY: Cambridge University Press. pp. 198-224.

Dowbiggin, I. R. (2003). A merciful end: The Euthanasia movement in modern America, Oxford England. New York, NY: Oxford University Press.

Emanuel, E. J. (1994). Euthanasia: Historical, ethical, and empiric perspectives. Archives of Internal Medicine, 154, 1890-1901.

Flemming, R. (2005). Suicide, euthanasia and medicine: Reflections ancient and modern. Economy and Society, 34, 295-321.

Fleming v. Ireland. (2013). IESC 19 (BAILII).

Griffiths, J., Weyers, H., \& Adams, M. (2008). Euthanasia and law in Europe. Oxford: Hart.

Hacking, I. (2008). The suicide weapon. Critical Inquiry, 35, 1-32.

Jackson, P. T. (2014). Making sense of making sense. Configurational analysis and the double hermeneutic. In D. Yanow \& P. Schwartz-Shea (Eds.), Interpretation and method: Empirical research methods and the interpretive turn (pp. 267-283). Armonk, NY: M.E. Sharp.

Johnston, J. (2015). New Zealand case and New York Times magazine article draw attention to physician aid in dying. The Hastings Center. Bioethics Forum.

Latour, B. (2010). The making of law: An ethnography of the conseil D'Etat. Malden, MA: Polity Press.

Lavi, S. J. (2007). The modern art of dying: A history of euthanasia in the United States. Princeton, NJ: Woodstock, Princeton University Press.

Livne, R. (2014). Economies of dying: The moralization of economic scarcity in U.S. hospice care. American Sociological Review, 79, 888-911.

Lynch, M. (1998). The discursive production of uncertainty: The OJ Simpson 'dream team' and the sociology of knowledge machine. Social Studies of Science, 28, 829-868.

Marvasti, A. B. (2004). Qualitative research in sociology: An introduction. London: SAGE.

Mather, L. (1998). Theorizing about trial courts: Lawyers, policymaking, and tobacco litigation. Law and Social Inquiry-Journal of the American Bar Foundation, 23, 897-940.

Miles, M. B., \& Huberman, A. M. (1994). Qualitative data analysis: An expanded sourcebook. Thousand Oaks, CA: Sage. 
Oregon Health Authority. (2006). Death with dignity act requirements. Retrieved June 11, 2015, from https://public.health.oregon.gov/ProviderPartnerResources/EvaluationResearch/ DeathwithDignityAct/Documents/requirements.pdf

Pfohl, S. (2008). The reality of social constructions. In J. A. Holstein \& J. F. Gubrium (Eds.), Handbook of constructionist research (pp. 645-668). New York, NY: The Guilford Press.

Potter, J. (1996). Representing reality: Discourse, rhetoric and social construction. London: Sage.

Scheffer, T. (2007). Statements, cases, and criminal cases. The Ethnographic Discourse Analysis of Legal Discourse Formations. Forum qualitative Sozialforschung/forum: Qualitative social research, 8(2), 1-7.

Seale, C. (1998). Constructing death: The sociology of dying and bereavement. Cambridge: Cambridge University Press.

Seymour, J. E. (2007). Windows on suffering: Sociological perspectives on end of life. Medical Sociology Online, 2, 35-50.

Tierney, T. F. (2010). The governmentality of suicide: Peuchet, Marx, Durkheim, and Foucault. Journal of Classical Sociology, 10, 357-389.

Timmermans, S. (2005). Death brokering: Constructing culturally appropriate deaths. Sociology of Health \& IIIness, 27, 993-1013.

Van Hooff, A. J. (2004). Ancient euthanasia:'Good death'and the doctor in the graeco-Roman world. Social science \& medicine, 58, 975-985.

Venturini, T. (2010). Diving in magma: How to explore controversies with actor-network theory. Public Understanding of Science, 19, 258-273.

Walker, G. C. (2003). Medical euthanasia. In C. D. Bryant (Ed.), Handbook of death \& dying (pp. 405-423). Thousand Oaks, CA: Sage.

Walter, T. (1994). The revival of death. London: Routledge.

Wolf, S. M. (1997) Pragamatism in the face of death: The role of facts in the assisted suicide debate. Minnesota Law Review, 82, 1063-1101.

Wright, D. K., Fishman, J. R., Karsoho, H., Sandham, S., \& Macdonald, M. E. (2015). Physicians and euthanasia: a Canadian print-media discourse analysis of physician perspectives. CMAJ Open, 3, E134-E139.

Youk, T. (2004). Pioneers of hospice: Changing the face of dying. 49 min.: Fanlight Productions. 